\title{
THE CASE OF THE DISAPPEARING FLUID
}

\author{
R. McCuTCHEON, M.D., F.R.C.P.(c)
}

Carbocanne (Mepivacaine) hydrochlorude has proved to be a useful local anaesthetic agent because of its competent analgesia, its low toxicity, and its prolonged action without adrenaline. A 2 per cent solution has been used exclusively for obstetrical anaesthesia at the Toronto Northwestern General Hospital, a 20 c.c. vial being autoclaved with the epidural tray. The usual procedure at this hospital for obstetrical analgesia consists of a single epidural injection of 15 to 20 c.c. of 2 per cent carbocaine hydrochloride just prior to delivery.

It had been noticed upon opening the tray that vials not uncommonly contained less than the 20 c.c. originally present, sometimes as little as 10 c.c. Delay in producing a second vial of carbocaine was disturbing in those cases where speed was necessary. A study was therefore undertaken to discover the cause of the loss of the fluid.

Suspicion was directed towards the autoclaving procedure, and flaws in the sealing of the vial, since not all carbocaine vials lost fluid, and no other local anaesthetic agent showed this feature. There are two methods of sterilization used in this hospital. The orthovac high-speed method begins with $17 \mathrm{lb}$. per square inch of negative pressure, followed by the rapid introduction of steam to $275^{\circ} \mathrm{F}$. for three minutes, a further negative pressure of $17 \mathrm{lb}$. per square inch, and finally a rapid return to normal pressure. This procedure takes twenty minutes to complete. The gravity convection, or slow sterilization method introduces steam to $250^{\circ} \mathrm{F}$. for 30 minutes followed by a slow return to normal temperature and pressure. One hour is required for this process.

Thirty vials of 2 per cent carbocaine hydrochloride were sterilized by each method and any decrease in volume was measured following cooling. There was no loss of fluid in any of the vials sterilized by the slow method, but eight of the thirty vials sterilized by the rapid method showed less than the original volume marked prior to autoclaving. The residual volume varied between 10 and 17 c.c., with an average of 14 c.c.

\section{CONCLUSION AND SUMMARY}

Twenty-seven per cent of the rapid sterilization group showed significant loss of fluid. This contrasted with no loss in the slow sterilization procedure. It appears that the negative pressure used in this method draws fluid from the carbocaine vials. An examination of the sealing mechanism of xylocaine and carbocaine vials revealed a tighter seal with thicker rubber in the xylocaine vial. This sealing withstood the negative pressure of the orthovac sterilization, unlike that of the carbocaine stopper. It is recommended that carbocaine vials be sterilized by a slow autoclaving process without negative pressure. 


\section{RÉSUMÉ}

En nous servant de la pression négative durant la stérilisation rapide à l'autoclave nous avons constaté la perte de carbocaïne dans des vials scellés. Avec la stérilisation lente, nous n'avons pas observé ce fait.

\section{ACKNOWLedgMents}

I would like to extend thanks to Mrs. Phyllis Gabel of Winthrop Laboratories and Mr. William Gage of the engineering department at Northwestern General Hospital for their help. 